\title{
Electrochemical Studies on the Stability and Corrosion Resistance of Two Austenitic Stainless Steels for Soft Drinks Containers
}

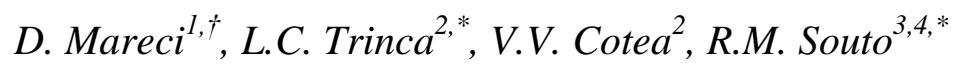 \\ ${ }^{1}$ Department of Chemical Engineering, "Gheorghe Asachi” Technical University of Iasi, 700050 Iasi, \\ Romania \\ ${ }^{2}$ Exact Sciences Department, "Ion Ionescu de la Brad” University of Agricultural Science and \\ Veterinary Medicine, 700490 Iasi, Romania \\ ${ }^{3}$ Department of Chemistry, Universidad de La Laguna, E-38205 La Laguna, Tenerife, Canary Islands, \\ Spain \\ ${ }^{4}$ Instituto Universitario de Materiales y Nanotecnologías, Universidad de La Laguna, E-38200 La \\ Laguna, Tenerife, Canary Islands, Spain \\ ${ }^{\dagger}$ Deceased on January 8, 2017. \\ "E-mail: rsouto@ull.es, lctrinca@yahoo.com
}

doi: $10.20964 / 2017.06 .35$

Received: 31 January 2017 / Accepted: 5 April 2017 / Published: 12 May 2017

\begin{abstract}
Austenitic stainless steel alloys are used in different food industry applications, including the preparation and storage of acidified carbonated soft drinks. Yet, austenitic stainless steels are not inert materials in contact with these drinks, and eventual modifications of these alloys must be investigated. Three carbonated soft drinks were investigated as for their effect on the stability of $\mathrm{FeCrNi}$ and FeCrNiMo alloys using two electrochemical techniques, namely linear potentiodynamic polarization (LPP) and electrochemical impedance spectroscopy (EIS), at $25^{\circ} \mathrm{C}$. The high corrosion resistance of the austenitic stainless steel alloys in the soft drinks was provided by the formation of a rather stable passive film formed by metal oxides. Also, the electrochemical behaviour was related to an inhibitory action by caffeine as evidenced using potentiodynamic polarization and electrochemical impedance spectroscopy methods, with good correlations between them.
\end{abstract}

Keywords: Stainless steel; Beverages; Corrosion resistance; Electrochemical characterization; Surface analysis; Scanning electron microscopy (SEM).

\section{FULL TEXT}


(C) 2017 The Authors. Published by ESG (www.electrochemsci.org). This article is an open access article distributed under the terms and conditions of the Creative Commons Attribution license (http://creativecommons.org/licenses/by/4.0/). 